\title{
Analysis of district oral health services in KwaZulu-Natal
}

\author{
Dookie $\mathrm{S}^{1}$, Singh $\mathrm{S}^{1} \&$ Myburgh $\mathrm{NG}^{2}$ \\ ${ }^{1}$ Discipline of Dentistry, School of Health Sciences, \\ University of KwaZulu-Natal, South Africa \\ ${ }^{2}$ University of the Western Cape \\ singhshen@ukzn.ac.za
}

\begin{abstract}
There is very little published data on public oral health services in KwaZulu-Natal (KZN). This paper analyzes oral health service delivery within the Department of Health in KZN.

Methods

The study used an in-depth, analytical and mixed methods approach with a combination of primary and secondary data. The primary data included telephonic interviews. The secondary data comprised a review of health policy documents and statistical records on oral health services in KwaZulu-Natal. Document review comprised II purposively selected national and provincial health and oral health policy documents. Structured telephonic interviews were conducted with purposively selected district oral health managers $(n=10)$. Statistical records for the period 2010 to 2012 were obtained from the KZN District Health Information System. Data analysis included content analysis for the health policy documents and thematic analysis for the interview data. The quantitative data was analyzed using the statistical software package for social sciences SPSS version 23.0.

Results

Five of the reviewed policy documents made reference to oral health care. The majority of the interview participants indicated that oral health service delivery in KwaZulu-Natal was inadequate. The themes that arose from data analysis included lack of human resources, dental equipment and consumables, and inadequate dental education and promotion programmes. Data on oral health service delivery indicated imbalances in the distribution of dental facilities and oral health workers. Although there was an increase in dental visits for the required period, dental extractions remained the most frequent clinical procedure.

Conclusion

There is an urgent need to re-orient oral health service delivery with a stronger commitment to disease prevention and oral health promotion.
\end{abstract}

Keywords: oral health; primary health care; district health services; policy

\section{Introduction}

Poor oral health and untreated oral diseases impact significantly on the quality of life and is considered a major public health problem (Petersen 2004; Petersen 2008). Oral health policy transformation in post-apartheid South Africa has been very closely aligned to health transformation efforts, given that both health and oral health share the same underlying determinants (namely, socioeconomic status, lifestyle, access to health care services, employment) that influence disease and ill-health (Singh, Myburgh and Lalloo 2010). Although access to oral health services remain a prioritized area in national and provincial oral health policy documents (Department of Health 2010, Rispel 2010, Department of Health 20I3a), there is very little literature in KwaZulu-Natal and South Africa that actually examines oral health systems response to improving access oral health care. Primary oral health care refers to the reduction of risk factors for dental caries and periodontal disease through the promotion of healthier lifestyles within a framework on general healthy living; reduction in sugar consumption; exposure to additional fluoride uptake and dental sealant programmes (Ayo-yusuf et al 2007; Van Wyk and Van Wyk 20I0). These strategies and interventions can focus on both the individual and the population at large (Ayo-yusuf et al 2007).

\section{Health care reform}

The development and implementation of the National Health Insurance (NHI) scheme is designed to address the historical imbalances in health care 
provision through a health financing system aimed at improving the quality of health care delivery in the country (Department of Health 20II; Oni et al 2014). The NHI represents one area of health care reform directed at improving access to health care. It is expressed in both the Constitution of South Africa (Act 108 of 1996) and the National Health Act (Act 6I of 2003), and embeds the goal of the Alma-Ata's Health for All (Dhai 20II). Other principles of the $\mathrm{NHI}$, include effectiveness, equity, appropriateness, affordability efficiency, and social solidarity (Department of Health 20IId). The NHI White Paper thus places primary health care (PHC) reengineering at the heart of health reforms (Gray et al 2013). The management of non-communicable diseases, including oral health, forms part of this strategy (Department of Health 20/3). Reengineering of $\mathrm{PHC}$ in the South African context looks at strengthening district health systems through the creation of ward-based district PHC teams; district-based specialist teams and school health services (Rispel 2010; Schaay et al, 20II; Pillay and Barron 2012). This has relevance to the oral health context of public service delivery. Historically the delivery of oral health services in South Africa, has been urban-based and curative driven (Gugushe 1998) with stark imbalances in the quality of oral health care occurring between provinces, and between different districts within a province (Singh, Myburgh and Lalloo 2010). These imbalances and inequities in oral health service delivery are quite alarming given that the measures to improve oral health status are simple, cost effective and easy to implement (Van Wyk and Van Wyk 2004). The White Paper for NHI points out that the two-tier health system (namely public and private health care) had resulted in a skewed imbalance in the distribution of health care workers. This is also relevant to oral health care. Almost $80 \%$ of the oral health workforce is located in the private sector while $20 \%$ of the oral health workforce provides services to $80 \%$ of the population dependent on public oral health care (Van Wyk and Van Wyk 2004; Department of Health 20IIc). However, the $\mathrm{NHI}$ initiative is not without criticism. Critics highlight the challenges of a single payer system for universal coverage; loss of autonomy in the management of private health practice settings, poorly managed resources, limited funding, and inability to address the current poor standards in public health care (Schaay et al, 20II; Amado et al 2012).

This study arose out of a need to understand the extent to which the oral health system is responsive to the larger health policy transformative landscape in South Africa. The aim and objectives of this study was to analyze public oral health service delivery in KwaZulu-Natal.

Applying a conceptual framework to oral health policy analysis

The analysis of oral health systems could benefit from a clearly defined framework that examines oral health policy development, implementation and oral healthrelated outcomes (Singh 2005; Hardee et al 20I2). The following should be considered when developing a framework for oral health policy analysis: The intersection between oral health policy priorities and collaboration among the different sectors responsible for improved health outcomes, should be examined in relation to the capacity to implement these policies (Singh, Myburgh and Lalloo 2010). Resources, infrastructure, financing and local oral health priorities could impact on the implementation process (Figure I). Concurrently, the selection of oral health interventions; mode of oral health service delivery (fixed facilities or mobile units); and the use of population based versus individual strategies, could also impact on the oral health outcomes (Figure I below). 


\section{Conceptual Framework: Link Between Health Policy, Health Systems \& Outcomes}

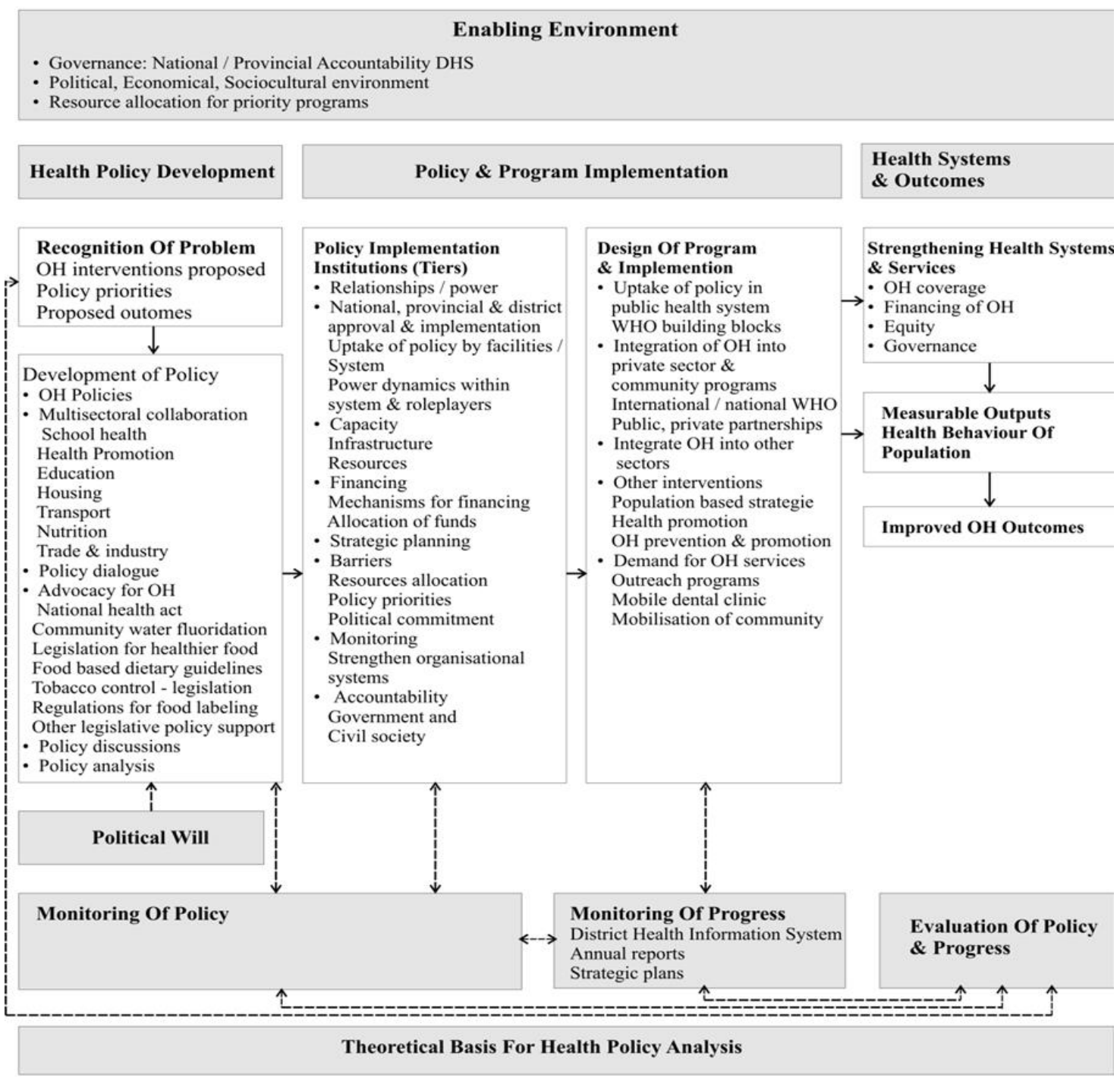

Source : Adapted from Hardee et al 2012:6

\section{Data and methods}

The study used an in-depth, analytical and mixed methods approach with a combination of primary and secondary data. The primary data was qualitative in nature and involved the use of telephonic interviews. The secondary data comprised a review of health policy documents (qualitative data) and statistical records (quantitative data) on oral health service delivery in KwaZulu-Natal. The data collection process was guided by a conceptual framework (Figure I).

Document review comprised II purposively selected national and provincial health and oral health policy documents developed after 1994 (Table I).

Structured telephonic interviews were conducted with a purposively selected oral health manager within the 10 districts in KZN, namely Amajuba, eThekwini, llembe, Sisonke, Ugu, Umkhanyakude, Umzinyathi, Uthukela, Uthungulu and Zululand. The selection criteria for the district oral health managers $(n=10)$ included those directly involved in oral health
The review focused on the following: Locating elements of primary oral health care in the identified health/oral health policy document; identifying the context in which these statements are expressed; and identifying policy priorities and objectives related to primary oral health care. The documents were selected on the assumption that oral health elements or expressions could be identified, given the close relationship between health and oral health, e.g. The National Food based Dietary guidelines for healthy South Africans older than 6 years (2003) looks at dietary recommendations and oral health care is influenced by dietary intake, specifically the type of carbohydrates consumed.

management and decision-making at district level. Gatekeeper permission was obtained from the KZN Provincial Health Research Committee (HRKM25/I2). Ethics approval was obtained from the University of KwaZulu-Natal Humanities and Social Sciences Research Ethics Committee (HSS/I306/0IID). The interview focused on oral 
health managers' perspectives of the extent to which the PHC framework is used in health policy documents; impact of this approach on oral health service delivery; strategies to improve oral health service delivery; universal coverage of oral health care; multisectoral collaboration; partnership development; methods of improving oral health related goals and outcomes, utilization of resources and equitable delivery of oral health care. The interviews were $60-90$ minutes in duration and were scheduled in accordance to the participant's availability. Informed consent was obtained from all participants and ethical considerations such as respect for persons, confidentiality and data security were adhered to. All interviews were audiorecorded.

Statistical records for the period 2010 to 2012 were obtained from the KZN District Health Information System for the ten districts in KwaZuluNatal. Data collection included the number of dental visits, number of oral health personnel, curative services (extractions, restorations) and prevention and promotion services offered (fissure sealants, tooth brushing programme, oral health education, schools visits). A data extraction sheet was used to record the collected data.

Content analysis was conducted on the health policy documents. Thematic synthesis was used to analyze the interview data. The interview notes were transcribed verbatim. The analysis process involved defining the analysis; classifying the data and then tagging or coding the data. These codes were inductively formed and the coded data was grouped for further analysis. The interview data was further divided with respect to its relevance or irrelevance to the study and labelled accordingly (Thomas 2008; Bazeley 2009). The final step entailed connecting the themes and the data as well as the ideas that evolved from this data to construct a valid argument in the reporting of the results obtained. The participants were requested to read the transcripts of the interview to assess if what they had said matched what was correctly captured and a verification of the theories and inferences that were formulated (Shenton 2004). This enhanced the credibility and reliability of the analyzed data.

The quantitative data was analyzed using the statistical software package for social sciences SPSS version 23.0. Univariate descriptive statistics such as frequency and mean distribution were conducted for the categorical data. The number of dental facilities and oral health personnel in each district was compared with the population figures in the district, as well as the number of tooth brushing programmes conducted, and the number of schools visited. Validity and reliability was maintained by ensuring that the collected data was related to the objectives of the study.

Table I: Selection of oral health and other policy documents

\begin{tabular}{|c|c|c|}
\hline & Oral Health Policy & Health Policy \\
\hline National & $\begin{array}{l}\text { - The South African National Oral Health } \\
\text { Strategy (2009) } \\
\text { - The primary oral health care package for } \\
\text { South Africa- National Norms, Standards and } \\
\text { Practice Guidelines for Primary Oral Health } \\
\text { Care (2007) }\end{array}$ & $\begin{array}{l}\text { - South African regulations for PPP (Regulation } \\
\text { 16) } \\
\text { - National food based Dietary guidelines for } \\
\text { healthy South Africans older than } 6 \text { years } \\
\text { (2003) } \\
\text { - Policy Guidelines for Community (Based) } \\
\text { health workers in South Africa (Draft 1997) } \\
\text { - A comprehensive primary health care service } \\
\text { package for South Africa (2010) } \\
\text { - Health Promotion } \\
\text { - Maternal, Child and Women's Health Care } \\
\text { Policy (1995) }\end{array}$ \\
\hline Provincial & $\begin{array}{l}\text { - The Kwa-Zulu Natal Oral Health Plan 20I I- } \\
2015\end{array}$ & $\begin{array}{l}\text { KwaZulu- Natal school health policy and } \\
\text { implementation guidelines (2004) } \\
\text { - Policy Guidelines on Youth and Adolescent } \\
\text { Health (200I) }\end{array}$ \\
\hline
\end{tabular}

\section{Results}

\section{Health policy document analysis}

The results of document review indicated that the Draft South African National Oral Health Strategy (2010) and Draft KZN Oral Health Plan 20II-20I5 made explicit references to oral health care. The
Draft South African National Oral Health Strategy (2010) aimed at improving the oral health status of individuals and communities through the identification of national goals, and specific national, provincial and 
district functions. The policy priorities included prevention of oral disease through the implementation of water fluoridation; the integration of oral health into other policies and programmes such as maternal, child and women's health; nutrition and chronic diseases; collaboration with other programmes and sectors to address common risk factors of alcohol, smoking, excess sugars, unsafe sex and violence. The Draft South African National Oral Health Strategy (2010) proposed that oral health management has its own budget and that dental facilities should operate as cost centres.

Similarly, the Draft KZN Oral Health Plan 20II2015, outlined the Department of Health's 10- point plan which included comprehensive oral health promotion and prevention programmes that focused on fissure sealants; oral health education and screening; and school based initiatives such as tooth brushing programmes. The strategies included, pain and sepsis relief programmes, the reduction of the extraction: filling ratio, the provision of regional maxillofacial/oral surgery services, regional

orthodontic services, district rehabilitation (denture) services, provincial mobile dental clinics and the development of a centralized laboratory service. It also included collaboration/ partnership development with private practitioners and non-governmental organizations. The Plan outlined specific strategies for addressing the burden of oral diseases but there was no indication of the exact process for implementation. The document explicitly outlined that the extraction to restoration (fillings) ratio was $30: 1$ in $2005 / 2006$. This decreased to $25: 1$ in $2007 / 2008$ and then increased again to $28: 1$ in $2008 / 2009$. The Strategic Plan suggested that this fluctuation could be attributed to financial barriers, problems with the acquisition of dental materials and equipment and the lack of oral health personnel in the province. The vacancy rate of dental practitioners increased from $34.9 \%$ in $2007 / 08$ to $37.3 \% 2008 / 09$. The resultant impact was reduced availability of oral health services. The high vacancy rate of oral hygienists (5I.9\%) was also highlighted.

Other reviewed documents that made reference to oral health included the KwaZulu-Natal School Health Policy and Implementation Guidelines (2004); Policy Guidelines on Youth and Adolescent Health (200I) and The Draft Health Promotion Policy and Strategy (20/3). The rest of the reviewed documents made scant reference to no mention of oral health as indicated (Table 2).

Table 2: Analysis of health policy documents

\begin{tabular}{|c|c|c|c|c|}
\hline Policy document & $\begin{array}{l}\text { Explicit Oral } \\
\text { health } \\
\text { statement }\end{array}$ & $\begin{array}{l}\text { Implicit } \\
\text { reference to } \\
\text { oral health }\end{array}$ & $\begin{array}{l}\text { Context of the } \\
\text { statement on oral } \\
\text { health }\end{array}$ & $\begin{array}{l}\text { Opportunities to include } \\
\text { oral health statements }\end{array}$ \\
\hline $\begin{array}{l}\text { South African Regulation } \\
\text { PPP } \\
\text { (Regulation 16) }\end{array}$ & None & $\begin{array}{l}\text { No presence of } \\
\mathrm{OH}\end{array}$ & Not located & $\begin{array}{l}\text { The document is broad- } \\
\text { based, hence applicable to } \\
\mathrm{OH} \text { as well }\end{array}$ \\
\hline $\begin{array}{l}\text { KZN School Health policy } \\
\text { and } \\
\text { implementation guideline } \\
(2004)\end{array}$ & $\begin{array}{l}\text { Strategy in } \\
\text { school health } \\
\text { programmes } \\
\text { screening }\end{array}$ & $\begin{array}{l}\text { Yes, makes } \\
\text { mention of oral } \\
\text { health }\end{array}$ & $\begin{array}{l}\text { Health assessments, } \\
\text { screening } \\
\text { health promotion and } \\
\text { education }\end{array}$ & $\begin{array}{l}\text { Health promotion } \\
\text { Health Prevention }\end{array}$ \\
\hline $\begin{array}{l}\text { MCWH Policy Document } \\
(1995)\end{array}$ & none & $\begin{array}{l}\text { No, presence of } \\
\mathrm{OH}\end{array}$ & & $\begin{array}{l}\text { Provide } \mathrm{OH} \text { education } \\
\text { during prenatal and } \\
\text { postnatal care advocating } \\
\text { healthy behaviour and self- } \\
\text { care at home. }\end{array}$ \\
\hline $\begin{array}{l}\text { The National Food Based } \\
\text { Dietary Guidelines (2003) }\end{array}$ & $\begin{array}{l}\text { Guidelines for } \\
\text { reduced sugars } \\
\text { will assist in } \\
\text { reducing dental } \\
\text { caries }\end{array}$ & $\begin{array}{l}\text { No but linked } \\
\text { to oral health }\end{array}$ & $\begin{array}{l}\text { Promotion of healthy } \\
\text { lifestyles and reduced } \\
\text { sugars }\end{array}$ & $\begin{array}{l}\text { Health promotion, } \\
\text { education }\end{array}$ \\
\hline $\begin{array}{l}\text { The role of Community } \\
\text { Health Workers in South } \\
\text { Africa's Health System- } \\
\text { Draft }(2010)\end{array}$ & none & $\begin{array}{l}\text { No mention of } \\
\text { oral health }\end{array}$ & & $\begin{array}{l}\mathrm{OH} \text { added to the role of } \\
\text { community health worker } \\
\text { activities }\end{array}$ \\
\hline
\end{tabular}




\begin{tabular}{|l|l|l|l|l|}
\hline $\begin{array}{l}\text { Policy Guidelines for Youth } \\
\text { and Adolescent Health } \\
(2001)\end{array}$ & $\begin{array}{l}\text { Health } \\
\text { intervention } \\
\text { strategies and } \\
\text { priorities }\end{array}$ & $\begin{array}{l}\text { Yes oral health } \\
\text { included }\end{array}$ & $\begin{array}{l}\text { strategies, fluoridation } \\
\text { of water, OH } \\
\text { education and } \\
\text { promotion }\end{array}$ & $\begin{array}{l}\text { Health promotion and } \\
\text { prevention }\end{array}$ \\
\hline $\begin{array}{l}\text { Draft National Health } \\
\text { Promotion Policy and } \\
\text { Strategy (2013) }\end{array}$ & $\begin{array}{l}\text { Personal } \\
\text { hygiene } \\
\text { (practices) }\end{array}$ & $\begin{array}{l}\text { Yes oral health } \\
\text { included }\end{array}$ & Action areas & Health Promotion \\
\hline
\end{tabular}

\section{Interviews with oral health district managers}

The majority of the interview participants indicated that the delivery of oral health services in KwaZuluNatal was poor and inadequate. One participant suggested "It is certainly not up to standard. The status leaves a lot to be desired in terms of implementing" (Zululand interviewee). The participants identified several factors that may be limiting the delivery of oral health services. Participants expressed reasons such as "There are no clear goals directing oral health, what it is we need to achieve and what sort of intervention should be in place" (eThekwini interviewee). The ILembe participant emphasized that "oral health services are coordinated" but "some of the standards and norms are not carried out well" while the Sisonke participant stated that services had improved but the rehabilitation service (dentures) is needed as the "community in this district is very poor and this was unaffordable". These responses suggest unclear strategic directives on oral health policy implementation and perceived inconsistent coverage of oral health services.

Several other themes arose from data analysis. These included lack of oral health human resources, dental equipment and consumables; and a lack of dental education, promotion and prevention programmes. Oral health was not seen as a policy priority. One respondent emphasized that "Maybe when prioritized and when government and different levels, national, provincial and district see the importance then maybe we can improve $\mathrm{OH}$ services, and adequate resources will be provided." "They feel oral health is not life and death." (Ugu interviewee). A lack of policy commitment also impacted on resource allocation and the long-term sustainability of the implemented programmes. According to the research participants, there appeared to be no specific budget allocation for oral health delivery at the health facility level, hence there was no clear process for financing oral health care.

One oral health programme manager advised that to ensure universal coverage, there has to be equity in oral health human resource allocation "have to have equitable distribution of oral health personnel in the entire province. In this district it is a challenge on its own to get people to work here. Cities like eThekwini and Pietermaritzburg get the first preference; we are in the last priority list for people to come here. Can't force people to work, they come for a year and go. No continuity in terms of service delivery" (Zululand interviewee).

Four district managers indicated that the PHC philosophy/approach had resulted in improved oral health services and that the approach was working to some extent in their district. They suggested that "it is working hence we have the outreach programmes now that are done in the community. Not waiting for the community members to come and look for us, we are going out there and rendering service to them" (Sisonke interviewee). There was improved coverage of oral health services especially "into communities" (Umkhanyakude interviewee). Six managers indicated that the approach had not improved oral health services and was not working in their districts. Participants' comments included 'The appropriate resources need to be put in place then the approach would be working provided these are in place" (eThekwini interviewee). "For oral health services it is actually not working because not all PHC clinics have oral health services because of the lack of human resources" (Ugu interviewee). "The structures that should be there to improve services are not yet fully equipped" (Umzinyathi interviewee). "In fact going down the drain if we look at current indicators we are monitoring for oral health" (Zululand interviewee).

Participants suggested that strategies to improve universal coverage and access, multisectoral collaboration, community participation and partnership development should include the provision of adequate resources, investment in infrastructure, collaboration with other sectors and working with traditional healers, health teams and communities through integrated health care delivery systems.

\section{Statistical records on oral health services}

Data on the infrastructure at each facility revealed an imbalance in the distribution and number of dental facilities (Figure 2). 
Figure 2:

Dental facilities per 100000 per district

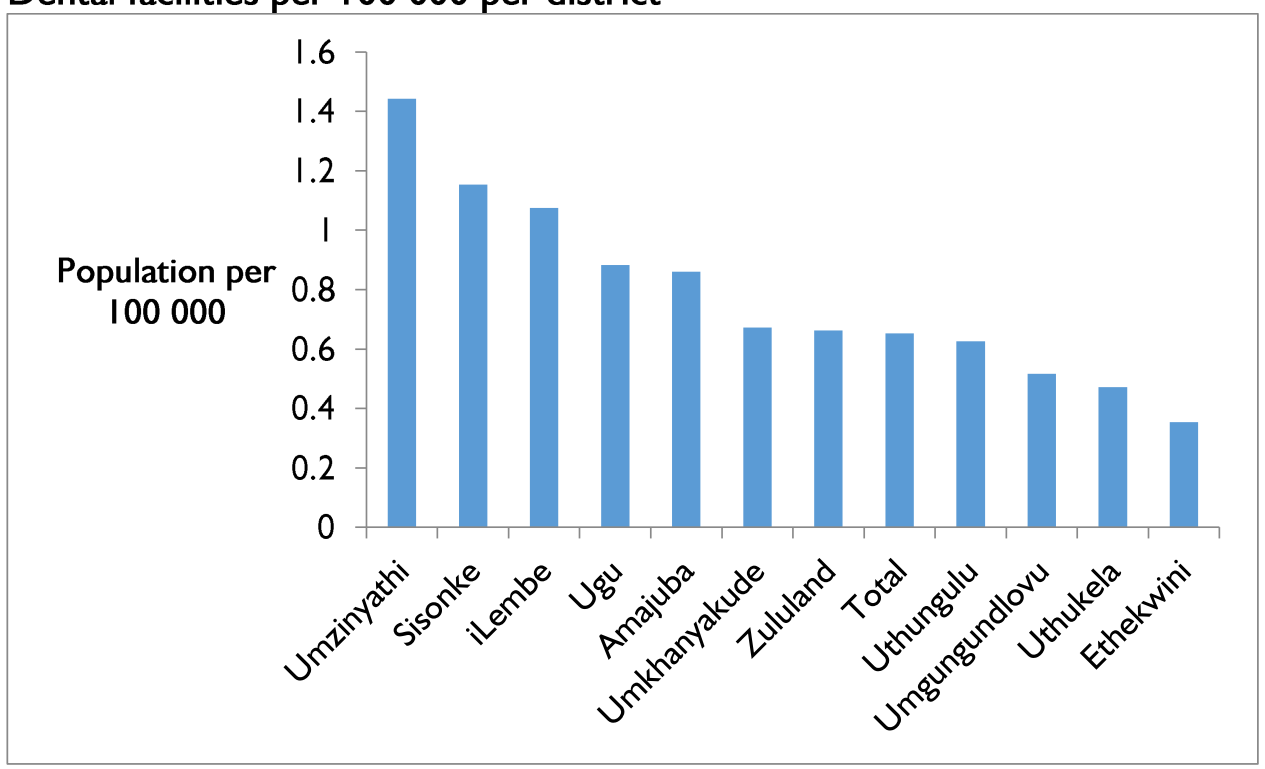

The number of fixed dental facilities in KZN was indicated per district: eThekwini (10), Umzinyathi (7), llembe (6), Ugu (6), Sisonke (5), Umgungundlovu (5), Uthungulu (5), Zululand (5), Amajuba (4), Umkhanyakude (4) and Uthukela (3). In total there were 60 dental facilities that offered oral health services to a population of $10,449,300$ in the province. About $52 \%$ of these facilities were located in district hospitals while $22 \%$ are located in community health care centres and $13 \%$ in primary health care clinics. The number of dental facilities per district suggest imbalances in the distribution of facilities between rural and urban districts. The districts that contained the main urban areas in KwaZulu-Natal (Ethekwini, Umgungundlovu, Uthukela) had the lowest number of dental facilities per 100000 . However, it has to be taken into account that these areas have the highest concentration of the uninsured provincial population (just over 48\%) (Department of Health 201 la). The data on oral health human resources also suggest an imbalance in the number of oral health workers in each district, as well as in each category of oral health worker (Table 3).

Table 3: Oral health personnel in KZN districts - 2012

\begin{tabular}{|l|l|l|l|l|l|l|l|}
\hline \multicolumn{1}{|c|}{ District } & $\begin{array}{l}\text { Oral } \\
\text { hygienist }\end{array}$ & $\begin{array}{l}\text { Dental } \\
\text { therapist }\end{array}$ & Dentist & $\begin{array}{l}\text { Community } \\
\text { service Dentist }\end{array}$ & CHW & Total & $\%$ \\
\hline Amajuba & 2 & $\mathrm{I}$ & 5 & $\mathrm{I}$ & 0 & 9 & 6.4 \\
\hline eThekwini & $\mathrm{I}$ & 8 & 26 & 5 & 0 & $4 \mathrm{I}$ & 29.1 \\
\hline iLembe & $\mathrm{I}$ & $\mathrm{I}$ & 6 & $\mathrm{I}$ & 0 & 9 & 6.4 \\
\hline Sisonke & 2 & 4 & 3 & 2 & 0 & 11 & 7.8 \\
\hline Ugu & 4 & 3 & 9 & 2 & 0 & 14 & 9.9 \\
\hline Umkhanyakude & 3 & 3 & 7 & $\mathrm{I}$ & 0 & 14 & 9.9 \\
\hline Umzinyathi & 3 & $\mathrm{I}$ & 4 & $\mathrm{I}$ & 0 & 9 & 6.4 \\
\hline Uthukela & $\mathrm{I}$ & $\mathrm{I}$ & 5 & $\mathrm{I}$ & 0 & 8 & 5.7 \\
\hline Uthungulu & 2 & $\mathrm{I}$ & 8 & 2 & 0 & 13 & 9.2 \\
\hline Zululand & 2 & 3 & 5 & 3 & 0 & 13 & 9.2 \\
\hline
\end{tabular}

Source: KwaZulu-Natal District Health Information System - 2012

Although Uthukela had the lowest number of oral health personnel, there was generally low numbers in oral health personnel in each district.
The dental utilization pattern for the province also revealed uneven rates. The total number of dental visits increased from 216072 to 233004 for the period 20I0/ 20I I and 20I I/20I2 (Table 4). 
Table 4: Data for KZN districts 20I0/20II- 20I I/20I2

\begin{tabular}{|l|l|l|l|l|l|l|l|l|}
\hline \multirow{2}{*}{ District } & \multicolumn{9}{|c|}{2010 -20II } & \multicolumn{3}{c|}{201 I-2012 } \\
\cline { 2 - 10 } & $\begin{array}{l}\text { Dental } \\
\text { visits }\end{array}$ & $\begin{array}{l}\text { Fissure } \\
\text { sealants }\end{array}$ & Extractions & Restoration & $\begin{array}{l}\text { Dental } \\
\text { Visits }\end{array}$ & $\begin{array}{l}\text { Fissure } \\
\text { sealants }\end{array}$ & Extraction & Restoration \\
\hline Amajuba & 1102 & 53 & 506 & 75 & 1183 & & 1091 & 67 \\
\hline eThekwini & 123675 & 10 & 92722 & 3059 & 120870 & 90 & 92384 & 2451 \\
\hline iLembe & 12340 & 4 & 9746 & 189 & 14962 & 38 & 11943 & 320 \\
\hline Sisonke & 5386 & 15 & 4574 & 112 & 10508 & & 10870 & 180 \\
\hline Ugu & 6049 & & 5307 & 2 & 7187 & & 8103 & 27 \\
\hline Umkhanyakude & 6547 & 68 & 6235 & 234 & 12693 & & 12346 & 81 \\
\hline Umzinyathi & 2243 & 14 & 1927 & 17 & 2184 & & 1856 & 111 \\
\hline Uthukela & 1902 & 24 & 1688 & & 3652 & & 3436 & 5 \\
\hline Uthungulu & 8748 & 31 & 7117 & 249 & 8993 & 101 & 7305 & 185 \\
\hline Zululand & 6722 & & 3461 & 21 & 7804 & & 7079 & 9 \\
\hline
\end{tabular}

Source: KwaZulu-Natal District Health Information System -2012

The most common clinical procedure was dental extractions. The data for oral health prevention and promotion programmes was sparse, inconsistent and unreliable. The number of dental extractions were much higher than the number of restorations done in the various districts. The records also indicated a modest increase in fissure sealant applications from 207 to 407, however these figures were far too low to have any kind of impact on preventive efforts in the province. Clearly there was a mismatch between the strategies outlined in the KZN Oral Health Plan 20II-20I5 and the delivery of oral health preventive services. The KZN Oral Health Plan clearly highlighted the need for a comprehensive fissure sealant programme as a key strategy to reverse the high rates of dental caries.

\section{Discussion}

Overall the results of this study suggested a mismatch between policy rhetoric and oral health service delivery in $\mathrm{KZN}$. While the national and provincial oral health policy documents are strong in content with clearly defined strategies on improving oral health outcomes, there is a lack of clarity on the implementation processes at district and institutional level, coupled with challenges in financial and human resource allocation. These findings are consistent with previous studies that also indicated challenges in the translation of oral health policy statements into implementable programmes that are capable of creating meaningful impact on oral health status (Singh, Myburgh and Lalloo 2010). Part of the challenge appeared to be linked to a lack of dedicated budget for oral health services. The results suggested that budgetary allocations are devolved to an institutional level and that oral health service delivery then has to compete with other health priorities. An http://aps.journals.ac.za understanding of the financial requirements related to oral health care is required to improve oral health service delivery. Further research in this area is essential to provide greater insight into the financing of oral health care.

\section{Access to oral health services}

The analysis of the data for oral health facilities suggested imbalances in the distribution and number of dental facilities within the districts, and an uneven distribution between urban and rural areas as well as within rural areas. The results also indicated that $52 \%$ of dental facilities are located in district hospitals and $35 \%$ in community health centres and clinics. In $\mathrm{KZN}$, patients are offered free services in the community health centres and clinics while hospitals implement a user fee. It is evident that the number of community health centres and clinics offering dental services are inadequate for the population of KZN and therefore could have the opposite effect in improving access for oral health care. The literature also indicates that despite the exemption of fee payment for disadvantaged individuals, the cost of transportation to the district hospitals could be a deterrent to the proper utilization of oral health services (Kautzkyk and Tollman 2009). This could inextricably have a negative impact on the effectiveness of service delivery as well as access to services. However, the literature also suggests that the causes of ineffectiveness and inaccessibility in health service delivery are multifactorial and not only related to the cost of transport (Mills 2006; Muhwava et al 2010). These costs form only one dimension to access. The other dimensions could include the coverage of services or the range of services that are available at the health facilities to meet the needs of the communities (Mills 2006). 
Thus there is an urgent need to decentralize oral health services to clinics and community health centres. This could assist in reducing costs and contribute to improved efficiency, accessibility and effectiveness of service delivery (Tollman et al 2006; Jamison et al 2006; Lopez et al 2006). Hospitals also consume a large part of the health budget as they offer diagnostic, treatment and rehabilitation services which often require better and costly equipment and more skilled personnel (The International Bank for Reconstruction and Development/The World Bank 2006). More investment in primary level infrastructure at clinics and community health centres could reduce costs to the patients/users such as transport costs but it is important that there are appropriate referral mechanisms for continuity of care (Rispel 2010; Gilson 2007; Mclntyre 2007; Mills 2006).

\section{Oral Health Human Resources}

The results of study also suggested that the lack of appropriate human resources was one of the main barriers to service delivery and has contributed to poor oral health service delivery. The number and distribution of oral health workforce across the various districts is worrisome. Other possible reasons for this mal-distribution include the "lack of funded public sector posts, lack of proactive planning for $H R$ " and poor management of the processes for recruiting these individuals that has made it unsuccessful in influencing health professionals to join the public sector (Department of Health $20 \mathrm{l} \mathrm{Ib:22-}$ 23). The training of oral health personnel has shifted towards primary health care but the personnel are still not sufficiently equipped for the many challenges of PHC and the flawed health system and cannot cope with challenges therefore leave the health system (Department of Health $20 \mathrm{I} \mathrm{Ib).}$

The data on dental therapists and oral hygienists in all the districts was especially low when compared to the dentists. The appropriate skills-mix is particularly important given that dental therapists and oral hygienists play a pivotal role in promoting primary oral health care services (Department of Health $20 \mathrm{llb})$. Dental therapists and oral hygienists have been trained as the mid-level workers in dentistry and have been identified as the appropriate oral health workers to implement the basic oral health care package of services (Hugo 2005). Dentists with their more specialized skills, could be better utilized at hospitals to provide specialized services however the study revealed that this was not occurring as the predominant service offered at all facilities was dental extractions. This places a further burden on scarce resources.
A practical solution to address the human resource shortage would be to increase the training of dental therapists and oral hygienists (Lehmann 2008; Department of Health 20I lb). Apart from increasing the oral health workforce, it is also necessary to explore other policy initiatives such as integrated oral health care (Peterson 2008). It is imperative to identify strategic entry points for oral health promotion efforts into other health programmes, such as school-based activities and mother and child programmes (Thema and Singh 2013). Simple oral health promotion messages, tooth brushing programmes and additional fluoride programmes can easily be conducted by other professionals such as educators, social workers, nurses and even community health care workers (Garland et al 20I2). The integration of oral health into nursing care at the primary care level is particularly important since $\mathrm{PHC}$ nurses form a vital component of the re-engineered PHC outreach team (Thema and Singh 2013.) Oral health is an integral component of general health, and basic oral health care should therefore be the responsibility of all health care workers (Garland et al 20I2). The anticipated $\mathrm{NHI}$ could also contribute to addressing the human resource shortage as health service provision would include accredited and contracted private sector health care providers (Department of Health 20I Id).

\section{Universal coverage of oral health services}

It is imperative that oral health services ensure that all individuals have access to basic oral health care (Rispel 2010; Department of Health 2010). The minimum package of care can only be effective if the services are offered consistently across all dental facilities. The minimum package for oral health care in South Africa includes prevention and promotion services, and treatment services. This includes an oral examination, cleaning and polishing of teeth, fissure sealant applications, dental extractions and simple fillings (Department of Health 20I0).

The results suggested that there was a skew towards dental extractions and that the extractionrestoration (filling) ratio was unacceptable. This demand for extractions requires further research to fully understand the possible factors that contribute this occurrence.

\section{Limitations of the study}

Although the study provides valuable insight into the plight of oral health service delivery in KwaZuluNatal, several limitations were noted. There was a lack of current publically available statistical records on oral health service delivery. There is an urgent need to strengthen the district health information systems to improve reporting of oral health services. 
The oral health plan for the province was still in draft form and was not available in the public domain. The study did not conduct a cost-utility and cost effectiveness analysis of oral health service provision in the province. Despite these limitations, the framework used was broad-based and flexible enough to be applied to other provinces in South Africa and to other countries of similar economic development.

\section{Conclusion}

There is an urgent need to reorient oral health services to a stronger focus on prevention of oral diseases and promotion of healthier oral health status.

Acknowledgment: KwaZulu-Natal Department of Health, South Africa

\section{Declaration of conflict of interest: None}

Author contribution: SD conceptualized the study, collected the data and was responsible for the writeup (50\%). SS was responsible for refining the aim, objectives and the methodological framework, and was responsible for supervising the study (35\%). NGM co-supervised the project was responsible for further conceptualizing and refining the research presentation (15\%).

Funding: SS received funding support from the College of Health Sciences Postgraduate funding programme, University of KwaZulu-Natal.

\section{References}

Amado L, Christofides N, Pieters R, et al. (20/2) National Health Insurance: A loft ideal in need of cautious planned implementation. The South African Journal of Bioethics and Law 5.

Ayo-Yusuf OA, Ayo-Yusuf IJ, Van Wyk PJ. (2007) Socio-economic Inequities in Dental caries. Experience of 12-year- old South African: Policy Implications for Prevention. South African Dental Journal I62 (I): 6-II.

Bazley D. (2009) Analysing quantitative data: More than identifying themes. Malaysian Journal of Qualitative Research 2: 6-22.

Dhai A. Healthcare reform in South Africa (20II). A step in the direction of social justice. The South African Journal of Bioethics and Law, 4(2).

http://www.sajbl.org.za/index.php/sajbl/article/view/I $8 \mathrm{I} / 155$

Department of Health. (2010) South African National Oral Health Strategy. Pretoria: Department of Health: I-I3.
Department of Health (20I la). Annual Performance Plan 20I I/20I2- 20I3/20I4. Department of KwaZulu- Natal Health. 20I I.

Department of Health. (20llb) Human Resources for Health South Africa 2030: Draft human resource strategy for the health sector 2012/2013-2016/2017. Pretoria: Department of Health: 3-27.

Department of Health. (20I Ic) KwaZulu-Natal Oral Health Plan 20II-20l4. KwaZulu-Natal: Department of Health.

Department of Health. (20IId) National Health Insurance in South Africa, Policy Paper. Pretoria: Department of Health.

Department of Health. (2013a) Strategic Plan for the Prevention and Control of Non-Communicable Diseases 2013-2017. Pretoria, Department of Health: 7-62.

Department of Health. (2013b) Annual Performance Plan 2013/2014-2015/ 2016. KwaZulu - Natal Department of Health: I-300.

Dookie S and Singh S. (20I2) Primary health services at district level in South Africa: A critique of the primary health care approach. BMC Family Practice 13: 1-4.

Garland T, Doherty M and Boulter S. (20/2) Integrating Oral Health into Primary Care. National Oral Health Conference May 2012: 12.

Gray A, Vawda Y and Jack C. (20/3) Health Policy and Legislation. In: Padarath A, English R, editors. South African Health Review 2012/2013. Durban: Health Systems Trust: 4.

Gilson L, Doherty J, Loewensen R, et al. (2007) Challenging inequity through health systems. Final Report. Knowledge Network on Health Systems. WHO Commission on the Social Determinants on Health.

Gugushe T. (1998) Compulsory community service audit for dentists in South Africa. Department of Health: 2- 4.

Hardee K, Irani L, Macinnis R, et al. (2012) Linking Health Policy with Health Systems and Health Outcomes: A conceptual framework. Washington, DC: Futures Group, Health Policy Projects: 2-6.

Hugo J. (2005) Health Workers in South Africa, not an easy option. Department of Family Medicine, Medical University of Southern Africa: 153.

Jamison DT, Breman JG, Measham AR, et al. (2006) Disease control priorities in developing countries. 2nd ed. New York: Oxford University Press.

Kautzkyk K and Tollman SM. (2009) A perspective of Primary Health Care in South Africa. Johannesburg: School of public health. University of Witwatersrand. Wits University press: 17-27.

Lehmann U. (2008) Strengthening human resources for primary health care In: Barron P, Roma- 
Reardon, J, editors. South African Health Review, Durban Health Systems Trust: 164- 174.

Lopez AD, Mathers CD, Ezatti M, et al. (2006) Global burden of disease and risk factors New York: Oxford University Press.

Mcintyre DL. (2007) Learning from experience: Health care financing in low-middle income countries. Geneva: Global Forum for Health Research.

Muhwava W, Hosegood V, Nyirenda M, Herbst K, Newell ML (2010). Levels and determinants of migration in rural KwaZulu-Natal, South Africa. African Population Studies 24(3): 259-280.

Mills A, Rasheed F and Tollman S. (2006) Strengthening health systems. In: Health Systems, editors. The International Bank for Reconciliation and Development/ The World Bank. Disease Control Priorities Project: 87-I00.

Oni T, McGrath N, BeLeu R, et al. (2014) Chronic Diseases and multi-morbidity- $\mathrm{A}$ conceptual modification to the WHO ICCC model for countries in health transition. BMC Public Health 14: 5 .

Petersen PE. (2004) Challenges to the improvement of oral health in the 2 Ist century- the approach of the WHO Global Oral Health Programme. International Dental Journal 54: 329-343.

Petersen PE. (2008) World health Organization global policy for the improvement of oral health- World Health Assembly 2007. International Dental Journal 58: || $|5-| 2 \mid$.

Pillay $Y$ and Barron P. (20I2) The implementation of Primary Health Care re-engineering in South Africa. Department of Health. Pretoria: I-6.

Rispel L. (2010) Re-engineering Primary Health Care in South Africa. Discussion Document, November 2010. Centre for Health Policy, School of Public Health, University of Witwatersrand: I-32.

Rispel L, Moorman J, Chersich M, et al. (2010) Revitalising primary health care in South Africa: review of primary health care package, norm and standards. Johannesburg: Centre for health policy, School of public health, Wits University. Johannesburg: Wits University Press: 33- 60.

Schaay N, Sanders D and Kruger V. (20I I) Overview of health sector reforms in South Africa.
Department for International Development (DFID), Human Resource Centre, London: 4-38.

Shenton AK. (2004) Strategies for ensuring trustworthiness in qualitative research projects. Education for Information. IOS Press 22: 63-75.

Singh S. (2005) A critical analysis of the provision for oral health promotion in South African health policy analysis. Full thesis submitted for the fulfillment of $\mathrm{PhD}$ in dental public health. University of Western Cape: I0- I50.

Singh S, Myburgh NG and Lalloo R. (2010) Policy analysis of oral health promotion in South Africa. Global Health Promotion 17: 22-25.

The Constitution of the Republic of South Africa. No 108 of 1996. Pretoria. I-77

The National Health Act No 6I of 2003. Pretoria 2003

The International Bank for Reconstruction and Development / The World Bank. (2006) Health Systems. Disease Control Priorities in Developing Countries: I-52.

Thomas J and Harden A. (2008) Methods for the thematic synthesis of qualitative research in synthesis of qualitative research in systematic reviews. BMC Medical Research Methodology 8: I-I0.

Thema LK and Singh S. (2013) Integrated primary oral health services in South Africa: The role of the $\mathrm{PHC}$ nurse in providing oral examination and education. African Journal for Primary Health Care, Family Medicine 5.

Tollman S, Doherty J and Mulligan J. (2006) General Primary Care. In: Health Systems, editors. The International World bank for Reconstruction and Development / The World Bank Disease Control Priorities Project: I I 93-I 195.

Van Wyk PG and Van Wyk C. (2004) Oral Health in South Africa. International Dental Journal 54: 373377.

Van Wyk C and Van Wyk PJ. (2010) Trends in dental caries prevalence, severity and unmet treatment need levels in South Africa between 1983 and 2002. South African Dental Journal 65 (7): 310314. 